\title{
OVERWEIGHT AND OBESITY AMONG ADOLESCENTS IN BELLARY CITY CORPORATION
}

\author{
T. Gangadhara Goud ${ }^{1}$, Ramesh $\mathrm{K}^{2}$
}

\section{HOW TO CITE THIS ARTICLE:}

T. Gangadhara Goud, Ramesh K. "Overweight and Obesity among Adolescents in Bellary City Corporation". Journal of Evolution of Medical and Dental Sciences 2014; Vol. 3, Issue 07, February 17; Page: 1718-1723, DOI: $10.14260 /$ jemds/2014/2048

ABSTRACT: BACKGROUND: Obesity is a complex condition with serious social and psychological dimensions, that affects virtually all age and socioeconomic groups and threatens to overwhelm both developed and developing countries. This problem is increasing in adolescents and various factors contribute to it. METHOD: A cross sectional study was conducted among 8, 9 and 10 standard students of high schools of Bellary city Corporation. The sample size was 792 and the technique adopted is stratified random sampling. Permission from respective authorities of schools was also taken. Data was collected using pre designed and pretested semi structured questionnaire which is self-administered. Body mass index was calculated based on physical measurements such as height and weight using standard methods. RESULTS: The prevalence of overweight and obesity is found to be $19.2 \%$. The prevalence of overweight alone is $12.4 \%$ and obesity is $6.8 \%$. Modifiable socio demographic factors are significantly associated with overweight/obesity. CONCLUSION: There is increased prevalence of overweight/obesity among adolescents and many factors associated with it are modifiable.

KEYWORDS: Overweight, Obesity, Body Mass Index.

INTRODUCTION: The countries of the South-East Asia Region are facing a double burden, with a heavy load of infectious diseases and an increasing burden due to NCDs. NCDs account for 51\% of all deaths and $44 \%$ of the disease burden in this Region (SEAR). ${ }^{1}$ The scenario in the beginning of $21 \mathrm{st}$ century has changed drastically, making NCD the major killer all over the world. This whole process of shift in disease pattern is leveled as Epidemiological transition.

Obesity can be seen as the first wave of a defined cluster of non-communicable diseases called "New World Syndrome" creating an enormous socioeconomic and public health burden in poorer countries $^{2}$. Obesity is a global nutritional concern. The increasing prevalence of overweight, obesity and its consequences prompted the World Health Organization to designate obesity as a global epidemic. World Health Organization's latest projections indicate that globally in 2005, approximately 1.6 billion adults were overweight and at least 400 million adults were obese. World Health Organization further projects that by 2015, approximately 2.3 billion adults will be overweight and more than 700 million will be obese ${ }^{3}$.

The problem of obesity is confined not only to adults but also to children and adolescents. Various studies also indicate that the prevalence of overweight and obesity amongst children of all ages is increasing in developing countries in the past few decades ${ }^{4,5}$. Figures on the global prevalence of childhood obesity have been compiled by the World Health Organization where several developing countries such as Nicaragua, Brazil, Antigua, Zambia, Venezuela and Peru, show a prevalence rate of over 2\%. Countries such as Barbados, Honduras, Lesotho, Bolivia, Trinidad, Iran and Mauritius have> 
$4 \%$ prevalence, while Jamaica and Chile top the list with $10 \%$ greater prevalence rate in school children6. There is only limited data on the prevalence of obesity among adolescents in India.

METHODOLOGY: This cross-sectional study was conducted among High schools of Bellary city Corporation, Karnataka during August 2013 to December 2013. The study population consisted of 8th, 9th and 10th standard students.

Selection of study subjects: Schools were stratified into Government, Private aided and Private unaided.

Stage - 1: one school each was selected randomly from each stratum (government/private aided/private unaided)

Stage - 2: once the schools were selected, all the study subjects were selected from each standard (8th, 9th and 10th).

Totally three schools were visited. The sample size was 792

Data was collected using a pre-tested self-administered questionnaire distributed in the classroom after telling them what the study is about and taking the verbal consent of the students. Each question was explained while the students filled them up with clarification of doubts. Questions were asked about identity, socioeconomic status, family history. Simultaneously, height and weight were measured.

Height was taken using a standard three piece anthropometric rod at their classrooms corrected up to $1 \mathrm{~mm}$. students were asked to stand upright against a wall with the heels touching the wall and the chin held horizontally so that the tragus of the ear and the eye are in a straight line, then the rod was adjusted and the height in $\mathrm{cm}$ was read. Weight of all students was taken using bathroom scales calibrated at the legal Metrology department and corrected with a lever balance up to $0.5 \mathrm{~kg}$ and calibrated daily for zero error. The students were asked to stand upright, bare footed on the weighing machine looking straight while the measurement was read. A measurement called percentile of Body Mass Index (BMI) is used to identify overweight and obesity in study subjects.

Body mass index is calculated based on physical measurements such as height and weight.

BMI = weight $(\mathrm{kg}) /$ height $(\mathrm{m}) 2$ National Centre For Health Statistics/CDC -2000 growth charts for children and adolescents aged 2-20 years i.e. BMI for age and sex percentile growth curves are used to classify the subjects as overweight and obesity.

The classification adopted in this study is, Weight Status Category Percentile Range

Underweight - Less than the 5th percentile

Normal weigh - 5thpercentile to less than the 85th percentile Overweight - 85th to less than the 95th percentile

Obese - Equal to or greater than the 95th percentile

Data was compiled using Microsoft Excel software and analyzed using SPSS.

RESULTS: A total of 792 students formed the study subjects, which included students from Government (33.8\%), Private aided (40.5\%) and Private unaided (25.6\%) schools. Students of $8^{\text {th }}$ standard, 9th standard and 10th standard constituted 32.5\%, 34.2\% and 33.3\% of study subjects' respectively. Study subjects included were both boys (58.3\%) and girls (41.7\%).

The age of the study subjects ranged from 12 to 16 years. Mean age of the subjects was 13.96 years (14.08 for boys and 13.84 for girls). 
The combined prevalence of overweight and obesity is $19.2 \%$. The prevalence of overweight alone is $12.4 \%$ and whereas obesity is $6.8 \%$. The prevalence of overweight/obesity increases with the age and is found to be high in the age group 15 yrs. The prevalence is high among girls (18.5\%) compared to boys (16.6\%) but it is not statistically significant (chi test, $\mathrm{p}=0.05$ ). Based on category of school, the prevalence is high among private unaided school students (25.2\%) compared to private aided (18.4\%) and government school (17.4\%) students. (Table-1 provides the results).

Prevalence of overweight/obesity is high among the subjects who belongs to family size (family members) up to four (20.5\%) compared to subjects who belong to family size more than four (16.3\%) and is more in students whose both the parents are working (36.9\%) compared to the students whose one of their parents (14.2\%) is working and none of their parents are working. The prevalence was high among families whose monthly income was more than 6000 Rs (26.2\%). Prevalence also increased with better occupation of father i.e. the prevalence is found to be high in those students whose fathers are in service sectors (27.3\%) compared to others and similar finding is observed with business/services occupation of mother $(73.9 \%)$.

Both father's and mother's educational qualification also showed a difference in the prevalence. The prevalence is high among those study subjects whose fathers are graduates and above (27.6\%) and also is high among those study subjects whose mothers are graduates and above (22.5\%).

DISCUSSION: The present study revealed that the combined prevalence of overweight and obesity is $19.2 \%$. Comparing the results of this study with other studies in India revealed that the prevalence of overweight is consistent with other studies whereas the prevalence of obesity is high.

The prevalence study of obesity among adolescents in public schools of Ludhiana, catering to the affluent segment of population, showed that $12.7 \%$ adolescents were overweight and $3.4 \%$ were Obese ${ }^{7}$. Another study carried out in Amritsar district of Punjab found that the prevalence of overweight is $10.94 \%$ and obesity $5.62 \%$. The high prevalence of overweight/obesity in adolescent is important because obese adolescents become obese adults thus increasing the risk of various diseases. This has been proved in many other studies in the past and is being researched even today to find the exact etiology.

In this study, it is also observed that the prevalence increases as the age increases. The prevalence peaked at 13, 14 and 15yrs. A school based study in Chennai done in adolescents showed that the prevalence peaked at 10,13 and 15 years $^{9}$ but whereas a study in Delhi showed that the maximum prevalence of obesity was at $10-12$ years ${ }^{10}$. It has been found that prevalence in higher ages of adolescents is reflective of overweight/obesity in adulthood ${ }^{11}$.

Study subjects included were boys and girls, girls showed a higher prevalence of obesity than boys. Similarly study conducted in Punjab also revealed that overweight was high among girls compared to boys.

Socioeconomic status may indirectly affect the development of overweight / obesity through the alteration of dietary habits / behaviors and physical activity patterns. In this study socioeconomic status of an individual is considered using proxy measures like occupation and education of father and mother, and family income. This study revealed that students who belong to family size up to four showed a risk of having overweight/obesity 1.68 times that of students of family size more than four. This was seen in the Delhi study where obesity was more in nuclear families ${ }^{12}$.It is probably due 
to more attention and pampering by the parents. The present study showed that the prevalence of overweight/ obesity is more among students who's both the parents are working compared to the students whose one of their parents is working and none of their parents are working. There is a significant difference in prevalence of overweight/obesity among the students' whose paternal and maternal occupation belongs to business/service sectors compared to others. A study conducted among school going adolescents in Wardha city, central India also revealed that father and/or mother involved in service/business sectors as the important correlate of overweight/obesity ${ }^{13}$. Numerous studies have shown this earlier ${ }^{14-16 .}$

The difference in prevalence is seen with paternal/ maternal education as in a study at Wardha city, central India, there was positive significant association between paternal/maternal better education and overweight/obesity among children. The possible explanation could be, better education means better job and therefore better socio economic status and it may also reflect the rearing up practices at home. A person with better education may want to bring up his/her children with better food. Children may have more pocket money and may eat more from outside especially bakery items and junk foods. The results of the present study are consistent with the results of other studies carried out in India.

The present study used category of the schools as one of the socio economic status indicator based on assumption that students of high economic status joins private schools.

The differences in types of school, Government, private aided and unaided was also examined and prevalence of overweight/obesity was found to be more in private unaided compared to aided and Government. Similarly a study carried out in Ernakulum, Kerala showed that the proportion of overweight children was significantly higher in private schools, and the rising trend was limited to private schools ${ }^{17}$.

CONCLUSION: The magnitude of overweight/obesity among high school students in Bellary City Corporation is high compared to other studies conducted in India. There is a significant association between Parents education, occupation and obesity.

\begin{tabular}{|c|c|c|c|c|c|}
\hline Variables & Underweight & Normal weight & Overweight & obesity & Total \\
\hline Overall & $165(20.8 \%)$ & 475 (59.9\%) & $98(12.4 \%)$ & $54(06.8 \%)$ & 792 \\
\hline Sex & & & & & \\
\hline Boys & $136(29.4 \%)$ & $249(53.9 \%)$ & $54(11.7 \%)$ & $23(04.9 \%)$ & 462 \\
\hline Girls & $71(21.5 \%)$ & $198(60.0 \%)$ & $41(12.4 \%)$ & $20(06.0 \%)$ & 330 \\
\hline Category of school & & & & & \\
\hline Government & $46(17.2 \%)$ & $175(65.3 \%)$ & $28(10.4 \%)$ & $19(07.0 \%)$ & 268 \\
\hline Private aided & $121(37.7 \%)$ & $141(43.9 \%)$ & $41(12.8 \%)$ & $18(05.6 \%)$ & 321 \\
\hline Private unaided & $21(10.3 \%)$ & $131(64.5 \%)$ & $28(13.8 \%)$ & $23(11.3 \%)$ & 203 \\
\hline
\end{tabular}




\begin{tabular}{|c|c|c|c|c|}
\hline Variables & $\begin{array}{c}\text { Overweight } \\
\text { /obese }\end{array}$ & $\begin{array}{c}\text { Non-overweight } \\
\text { /obese }\end{array}$ & Total & $P$ value \\
\hline $\begin{array}{l}\text { Family size } \\
\text { Up to } 4 \\
>4\end{array}$ & $\begin{array}{l}112(20.5 \%) \\
040(16.3 \%)\end{array}$ & $\begin{array}{l}434(79.5 \%) \\
206(83.7 \%)\end{array}$ & $\begin{array}{l}546 \\
246\end{array}$ & 0.001 \\
\hline $\begin{array}{l}\text { Working parents } \\
\text { One } \\
\text { Both } \\
\text { None }\end{array}$ & $\begin{array}{c}66(14.2 \%) \\
86(36.9 \%) \\
00\end{array}$ & $\begin{array}{l}399(85.8 \%) \\
147(63.1 \%) \\
094(100 \%)\end{array}$ & $\begin{array}{l}465 \\
233 \\
094\end{array}$ & 0.02 \\
\hline $\begin{array}{l}\text { Monthly income } \\
\text { Up to } 6000 \mathrm{Rs} \\
>6000 \mathrm{Rs}\end{array}$ & $\begin{array}{c}034(9.9 \%) \\
118(26.2 \%)\end{array}$ & $\begin{array}{l}298(90.1 \%) \\
332(73.8 \%)\end{array}$ & $\begin{array}{l}342 \\
450\end{array}$ & 0.001 \\
\hline $\begin{array}{l}\text { Father occupation } \\
\text { Unemployed } \\
\text { Unskilled } \\
\text { Semiskilled } \\
\text { Skilled } \\
\text { Service } \\
\text { Business \& others }\end{array}$ & $\begin{array}{c}04(11.7 \%) \\
09(10.7 \%) \\
03(6.9 \%) \\
08(10.5 \%) \\
96(27.3 \%) \\
32(15.8 \%)\end{array}$ & $\begin{array}{c}30(88.3 \%) \\
75(89.3 \%) \\
40(93.1 \%) \\
68(89.5 \%) \\
256(72.7 \%) \\
171(84.2 \%)\end{array}$ & $\begin{array}{c}34 \\
84 \\
43 \\
76 \\
352 \\
203 \\
\end{array}$ & 0.01 \\
\hline $\begin{array}{l}\text { Mother occupation } \\
\text { Housewife } \\
\text { Unskilled /semiskilled/skilled } \\
\text { Service \& others }\end{array}$ & $\begin{array}{l}65(11.9 \%) \\
70(31.4 \%) \\
17(73.9 \%)\end{array}$ & $\begin{array}{l}481(88.1 \%) \\
153(68.6 \%) \\
006(26.1 \%)\end{array}$ & $\begin{array}{l}546 \\
223 \\
023\end{array}$ & 0.03 \\
\hline $\begin{array}{l}\text { Father education } \\
\text { Up to SSLC } \\
\text { Pre degree } \\
\text { Graduate and above }\end{array}$ & $\begin{array}{l}62(19.3 \%) \\
32(12.3 \%) \\
58(27.6 \%)\end{array}$ & $\begin{array}{l}259(80.7 \%) \\
229(87.7 \%) \\
152(72.4 \%)\end{array}$ & $\begin{array}{l}321 \\
261 \\
210\end{array}$ & 0.40 \\
\hline $\begin{array}{l}\text { Mother education } \\
\text { Up to SSLC } \\
\text { Pre degree } \\
\text { Graduate and above }\end{array}$ & $\begin{array}{l}78(17.0 \%) \\
43(21.9 \%) \\
31(22.5 \%)\end{array}$ & $\begin{array}{l}380(83.0 \%) \\
153(78.1 \%) \\
107(77.5 \%)\end{array}$ & $\begin{array}{l}458 \\
196 \\
138\end{array}$ & 0.03 \\
\hline
\end{tabular}

\section{Table 2: Prevalence of overweight and obesity and Socio Demographic characters}

\section{REFERENCES:}

1. World health Organization. Non-communicable diseases in south East Asia region. Regional office for south East Asia, India, New Delhi: 2002.

2. World Health Organization. Special issues in the management of obesity in childhood and adolescence. Obesity Preventing and Managing the Global Epidemic, WHO, Geneva. 1998:231247.

3. Reilly JJ, Dorosty AR. Epidemic of obesity in UK children. Lancet. 1999; Nov27; 354(9193):1874-1875. 
4. Keil U, Kuulasmaa K. WHO MONICA Project: Risk factors. Int J Epidemiol. 1989; 18(Suppl 1):S46-S55.

5. Gurney M, Gornstein J. The Global Prevalence of Obesity --an Initial View of Available Data. World Health Statistics. 1998; 41: 251-254.

6. The Surgeon General's Call to Action to Prevent and Decrease Overweight and Obesity-2000.

7. Aggarwal T, Bhatia RC, Singh D, Sobti PC. Prevalence of obesity and overweight in affluent adolescents from Ludhiana, Punjab. Indian Pediatr.2008Jun; 45(6):500-2.

8. Sidhu S, Marwah G, Prabhjot. Prevalence of overweight and obesity among the affluent adolescent school children of Amritsar, Punjab. Coll Antropol. 2005 Jun; 29(1):53-5.

9. Subramanyam V, Jayashree R, Rafi M. Prevalence of overweight and obesity in affluent adolescent girls in Chennai in 1981 and 1998. Indian Pediatr. 2003 Aug; 40(8):775-9.

10. Kapil U, Singh P, Pathak P et al. Prevalence of obesity amongst affluent adolescent school children in Delhi. Indian Pediatr. 2002; 39: 449-452.

11. Valdez R, Greenlund KJ, Wattigney WA, et al. Use of weight-for-height indices in children to predict adult overweight: the Bogalusa Heart Study. International Journal of Obesity \& Related Metabolic Disorders: Journal of the International Association for the Study of Obesity. 1996; 20:715-721.

12. Bharati DR, Deshmukh PR, Garg BS. Correlates of overweight \& obesity among school going children of Wardha city, Central India. Indian J Med Res. 2008 Jun; 127(6):539-43.

13. Umesh Kapil, Preeti Singh, Priyali Pathak et al. Prevalence of Obesity amongst Affluent Adolescent School Children in Delhi. Indian Pediatrics. 2002; 39:449-452.

14. Robert C. Whitaker, Jeffrey A. Wright, Margaret S. Pepe, et al. Predicting Obesity in Young Adulthood from Childhood and Parental Obesity. New Eng J Med.1997; 337:869-873.

15. D.V.G.Nadgonda, Obesity: Prevalence, etiology and management. Nutr.Foun.India. 997;122-126

16. Paeratakul S., White MA, Williamson DA, et al. Sex, race/ethnicity, socioeconomic status, and BMI in relation to self-perception of overweight. Obes Res. 2002; 10: 345-350.

17. Raj M, Sundaram KR, Paul M, et al. Obesity in Indian children: time trends and relationship with hypertension. Natl Med J India. 2007 Nov- Dec;20(6): 288-93.

\section{AUTHORS:}

1. T. Gangadhara Goud

2. Ramesh K.

\section{PARTICULARS OF CONTRIBUTORS:}

1. Professor \& HOD, Department of Community Medicine, V.I.M.S, Bellary.

2. Assistant Professor, Department of Community Medicine, V.I.M.S, Bellary.
NAME ADDRESS EMAIL ID OF THE CORRESPONDING AUTHOR:

Dr. T. Gangadhara Goud, Professor \& HOD,

Department of Community Medicine, V.I.M.S, Bellary.

E-mail: gangadharagoud1@gmail.com

Date of Submission: 03/02/2014.

Date of Peer Review: 04/02/2014.

Date of Acceptance: 04/02/2014.

Date of Publishing: 13/02/2014. 